\title{
Effect of moderate exercise on bowel habit
}

\author{
G J Oettlé
}

\begin{abstract}
Ten healthy volunteers (six men and four women, aged 22-41 years) were studied in a crossover trial. The study was divided into three one week periods. During each period the subjects either ran on a treadmill, cycled on a bicycle ergometer, or rested in a chair for 1 hour every day. The exercise was performed at two thirds predicted maximum heart rate (equivalent to $50 \% \mathrm{Vo}_{2} \mathrm{max}$ ). The sequences were rotated; no studies were performed in the perimenstrual period. Transit was measured by the method of measuring the excretion of a single dose of radio-opaque markers; all stools were collected, weighed, and $x$ rayed after the ingestion of radio-opaque markers. Dietary fibre and fluid intake were measured on the fourth day of each test period by 24 hour record. Lifestyle was otherwise unchanged. Transit time was dramatically accelerated by moderate exercise (both jogging and cycling); however, stool weight, defecation frequency, dietary fibre intake, and fluid intake did not change significantly. Whole gut transit changed from 51.2 hours (95\% confidence intervals 41.9 to 60.5$)$ at rest to 36.6 hours $(31.6$ to 39.2$)$ when riding and 34.0 hours $(28.8$ to $39.2)$ when jogging. Riding and running both differed significantly from resting $(p<0.01)$; the difference between riding and running was not significant.
\end{abstract}

Considerable anecdotal experience suggests that submaximal exercise accelerates whole gut transit. Roald Dahl summarised what every general practitioner knows instinctively:

An early morning stroll

Is good for people on the whole.

It makes your appetite improve,

It also helps your bowels to move.

There is also the syndrome familiar to most runners (but not cyclists, canoeists, or swimmers) and often known as 'runners' trots'; this, however, usually occurs in the context of greater exertion than that carried out by the average jogger and may be mediated by different mechanisms. ${ }^{24}$

Few studies have attempted to define whether exercise has any measurable effect on bowel habit. This investigation assessed the effect of moderate exercise (jogging and cycling) on whole gut transit, stool weight, and defecation frequency. Dietary fibre and fluid intake were also measured, since it has been argued that any effects of exercise are indirect and mediated primarily by changes in these two components.

Subjects and methods

Ten healthy subjects, six men and four women aged 22-41 years, volunteered for the study
(Table I). The body mass index (Quetelet index, $\mathrm{kg} / \mathrm{m}^{2}$ ) was $18 \cdot 9-24 \cdot 9$. None of the subjects engaged in regular competitive running or cycling, although the majority were recreational cyclists, occasional joggers, or members of aerobics gyms. All were healthy, with no cardiorespiratory or gastrointestinal symptoms; bowel habit was, subjectively, not greatly irregular in any one.

The basic design of the study was a crossover trial, with each subject acting as his or her own control. The study was divided into three one week periods. During each week the subjects either ran on a treadmill, or cycled on a bicycle ergometer, or rested in a chair for 1 hour every day. The exercise was performed at two thirds predicted maximum heart rate (equivalent to $50 \% \mathrm{Vo}_{2}$ max. ${ }^{56}$ Heart rate was measured at 5 , $10,15,20,30,40$, and 50 minutes, and the speed of the treadmill or load on the ergometer adjusted at each time to maintain the heart rate at the required level.

The sample was too small to randomise sequences of activity. Instead, sequences were allocated to subjects in rotation, in an attempt to eliminate any knock-on effect of one or other period. Two subjects each carried out Rest-RideRun, Rest-Run-Ride, Ride-Rest-Run, and RunRide-Rest, while one each did Ride-Run-Rest and Run-Rest-Ride.

No studies were performed in the perimenstrual period since many women report altered bowel habit at this stage of their cycle, ${ }^{7-9}$ although some reports claim that there is no pronounced variation during the menstrua cycle. ${ }^{10}{ }^{11}$ In consequence the study weeks were not always consecutive. In addition, some subjects could not participate at particular times for various reasons and so also had their weeks delayed.

Whole gut transit was measured by the MTT-S method of Cummings et al. ${ }^{12}$ The exercise or rest started on a Monday afternoon. Fifty radioopaque plastic markers were swallowed late that evening (four to eight hours after the first episode of exercise), and all stools passed subsequently were timed, collected, weighed, and $x$ rayed until all markers had been passed. In every case the exercise or rest and stool collection continued for

\begin{tabular}{cllll} 
TABLE I & \multicolumn{4}{l}{ Details of subjects } \\
\hline $\begin{array}{l}\text { Age } \\
\text { Subject }\end{array}$ & years) & Sex & $\begin{array}{l}\text { Body mass index } \\
\left(\mathrm{kg} / \mathrm{m}^{2}\right)\end{array}$ & Occupation \\
\hline 1 & 34 & $\mathrm{M}$ & $18 \cdot 9$ & General practitioner \\
2 & 25 & $\mathrm{~F}$ & $19 \cdot 2$ & Librarian \\
3 & 40 & $\mathrm{M}$ & $20 \cdot 2$ & Surgeon \\
4 & 30 & $\mathrm{M}$ & $23 \cdot 2$ & Schoolmaster \\
5 & 41 & $\mathrm{M}$ & $24 \cdot 1$ & Urologist \\
6 & 22 & $\mathrm{~F}$ & $21 \cdot 1$ & Dietician \\
7 & 37 & $\mathrm{~F}$ & $20 \cdot 1$ & Physiotherapist \\
8 & 39 & $\mathrm{~F}$ & $19 \cdot 0$ & Anaesthetist \\
9 & 27 & $\mathrm{M}$ & $21 \cdot 0$ & Physician \\
10 & 34 & $\mathrm{M}$ & $24 \cdot 9$ & Haematologist \\
\hline
\end{tabular}


TABLE II Changes in whole gut transit time with exercise (hours)

\begin{tabular}{llll}
\hline & Mean & $95 \%$ confidence intervals & Median \\
\hline Rest & $51 \cdot 2$ & 41.9 to 60.5 & 49.3 \\
Ride & 36.6 & 31.6 to 41.6 & 34.0 \\
Run & 34.0 & 28.8 to 39.2 & 33.4 \\
\hline
\end{tabular}

Wilcoxon's signed rank sum test: rest $v$ ride $\mathrm{p}<0.01$; rest $v$ run $\mathrm{p}<0.01 ;$ ride $v$ run $\mathrm{p}>0.05$.

at least one day after the last marker was passed.

Dietary fibre and fluid intake were measured on the fourth day of each test period by a 24 hour record. These data were analysed using the MRC Food Tables. Apart from the exercise or rest, lifestyle was unchanged; there were no other restrictions placed on the subjects, except that they did no other 'exercise' (sport, games, jogging, cycling, swimming, gym, etc; any walking was only that which was unavoidable at work or at home) during the study periods and the two days before starting each period.

The study was approved by the Human Ethics Committee of the University of the Witwatersrand.

\section{Results}

Transit time was dramatically accelerated by the moderate exercise performed by the subjects (Table II, Figure). Remarkably, the other parameters of bowel function, stool weight, and defecation frequency (Table III), were not significantly affected. Dietary fibre consumption and fluid intake did not vary significantly either (Table IV), possibly because the level of exercise was very mild. All the subjects were able to talk all the time without any dyspnoea throughout both exercise periods.

\section{Discussion}

The intervention of this study was moderate exercise (or rest) for one hour per day for one week at a time. Laboratory exercise on a treadmill or bicycle ergometer was chosen because of the enormous number of uncontrollable variables in 'free' exercise - that is, jogging or road cycling. The workload could be precisely adjusted and continuously monitored and was accurately reproducible. A cycling arm was included to provide equivalent cardiovascular

TABLE III Defecation frequency (per day) and daily faecal excretion ( $g / d$ ) (mean (95\% confidence intervals))

\begin{tabular}{lll}
\hline & Defecation frequency & Daily faecal excretion \\
\hline Rest & $1.3(0.9$ to 1.7$)$ & $183(129$ to 237$)$ \\
Ride & $1.3(0.8$ to 1.8$)$ & $219(150$ to 288$)$ \\
Run & $1.4(0.9$ to 1.9$)$ & $185(147$ to 223$)$ \\
\hline
\end{tabular}

Differences not significant.

TABLE IV Dietary fibre intake (g/d) and fluid intake (l/d) (mean (95\% confidence intervals))

\begin{tabular}{lll}
\hline & Fibre intake & Fluid intake \\
\hline Rest & $19 \cdot 6(14 \cdot 4$ to $24 \cdot 8)$ & $1 \cdot 6(1 \cdot 2$ to 1.9$)$ \\
Ride & $20 \cdot 2(17.0$ to $23 \cdot 4)$ & $1 \cdot 5(1.5(1 \cdot 0$ to 1.9$)$ \\
Run & $22.5(16.6$ to $28 \cdot 4)$ & $1 \cdot 7(1.4$ to $2 \cdot 0)$ \\
\hline
\end{tabular}

Differences not significant.

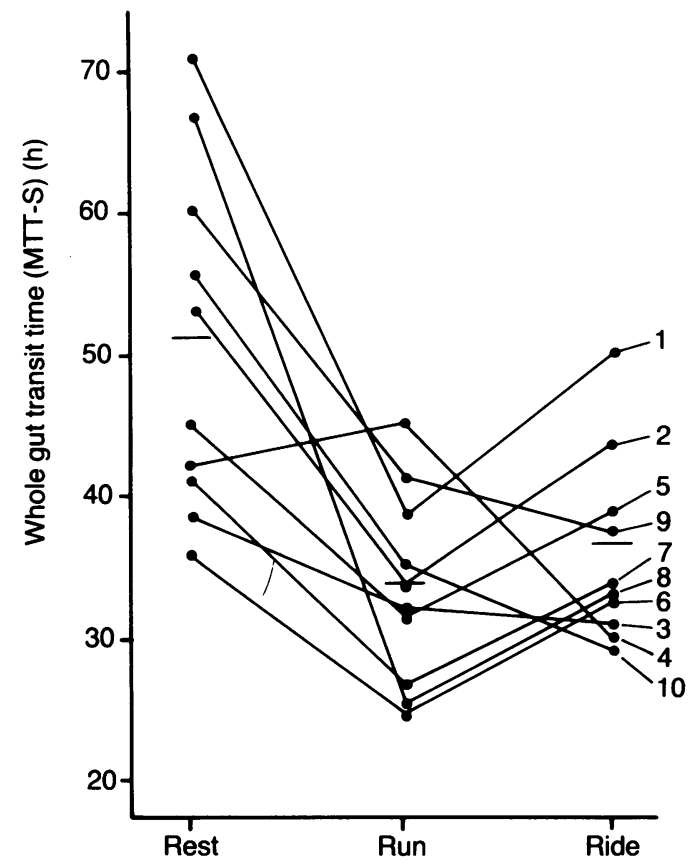

Effect on whole gut transit time of running, cycling, and resting. $M T T-S=$ mean transit time of dietary residue through the gut of single radio-opaque pellets.

stress to the visceral circulation, without the possible mechanical effects of jiggling the abdominal contents while running. The crossover design made it possible for each subject to be his or her own control. The sequences were rotated to eliminate any knock-on effect and to reduce the effect of temporal variation of bowel habit.

Heart rate is a good measure of relative workload. ${ }^{13}$ There is a consistent linear relation between heart rate and oxygen consumption $\left(\mathrm{Vo}_{2}\right) .^{56}$ The use of heart rate permits ready comparison as well as moment to moment adjustments of workload and cardiovascular stress. The unfit will obviously do less work for the same heart rate, but their exercise will provide comparable cardiovascular stress to that generated by their fitter colleagues.

Bowel habit, or whole gut transit, is a far from 'regular' phenomenon. Its considerable normal variability has been well documented..$^{10}$ In an attempt to minimise this effect sequences were rotated. It is unlikely that all 10 subjects would have simultaneously spontaneously accelerated their transit time as they moved to the exercise arms of the study.

The best method of determining transit is undoubtedly the MTT-C technique of Cummings and colleagues ${ }^{12}$ - continuous feeding of markers, and continuous stool collection, over a period of weeks. It is also the most inconvenient for the subjects. In this study the MTT-S method $^{12}$ was used instead, which depends on measuring the excretion of a single dose of markers. There is a good correlation with MTT$\mathrm{C}$, and the multiple stool collections aid accuracy.

An unresolved question is the independent effect of dietary fibre. Bingham and Cummings recently suggested that all of the alleged effects of exercise can be explained by alterations in ingested fibre. ${ }^{14}$ In a dietetically rigidly con- 
trolled study (including constant fibre intake), where the subjects lived in the Dunn Clinical Nutrition Centre, they could show no consistent effect of exercise. The exercise used, however, was uncontrolled, inconsistent, and variable. Also, despite a constant diet (determined before starting the exercise), and subsequent daily energy expenditure for six to nine weeks great enough to increase maximum aerobic capacity by nearly $50 \%$, their subjects' weight did not alter appreciably.

The present subjects were free living. On the fourth day of every period (after they had accustomed themselves to the exercise or rest) they kept a 24 hour record of all food eaten. This method is not ideal, but the repetitions provided for a certain degree of consistency, a relative if not absolute assessment.

The additional energy expenditure of the exercise was less than $2 \mathrm{MJ} /$ day (4-500 kcal/day), and although total energy and carbohydrate consumption increased concomitantly, the increases in dietary fibre (which were not in any case significant) were not biologically significant either - they were far too small to accelerate transit as much as in fact occurred.

Mild to moderate exercise has slight effects on gastric emptying (first noted by Beaumont in 1825) and small bowel transit. ${ }^{15-23}$ Nevertheless, these changes are minimal compared with the disproportionate contribution of the colon to total transit - between $75 \%$ and $90 \%$.

Most clinicians are aware of the costive effects of inactivity and hospitalisation or bed rest. The obverse is the familiar but unexplained phenomenon variously called 'runners' trots' or even the 'dumping syndrome.' This has been much discussed, ${ }^{2-4}$ though it is often confused with the extreme effects of exhaustion and mesenteric ischaemia. ${ }^{24-27}$ These urgent evacuations probably do not have much to do with the effect noted in this study, since no subject passed a stool during or shortly after the hour of exercise, and none had urgent evacuations at any stage. In addition, the study protocols were carried out under relatively non-stressful conditions, which were not really analogous to the psychological pressures of a race. Furthermore, competitive runners train and race at well over $75 \% \mathrm{Vo}_{2} \max$, while this study was conducted at a level closer to $50 \%$, when the reduction of visceral blood flow is very much less (see below).

The lack of change in defecation frequency is less puzzling than may appear because in the mid-range of transit and stool weight (35-60 hours, and 150-200 g/day) there is little correlation between defecation frequency and transit time. It is also not surprising that daily faecal excretion did not change, since dietary fibre, which is the main determinant of stool bulk through the stimulation of bacterial growth, did not change either. In other words, exercise had an independent effect on transit.

The mechanism of the acceleration of transit by moderate exercise is unclear, although there are perhaps four main possibilities - that it is through a reduction in visceral blood flow, hormonally mediated, neurogenic, or simply mechanical.

Visceral blood flow falls with exercise. At levels of exertion close to maximum the bowel may only receive $20 \%$ of its resting flow, though at $50 \% \mathrm{Vo}_{2} \max$ (as in this study) gut blood flow is maintained at $70 \%$ of normal. ${ }^{27-29}$ It is hard to imagine that reducing an organ's blood flow should improve its function; indeed, the effects are possibly even deleterious. ${ }^{2+26}$

Many hormone concentrations alter during exercise, including vasoactive intestinal polypeptide, secretin, pancreatic polypeptide and somatostatin,,$^{30}$ gastrin, ${ }^{31}$ glucagon, ${ }^{32}$ catecholamines, ${ }^{32-34}$ motilin, ${ }^{35}$ prostaglandins, ${ }^{36}$ and endorphins. ${ }^{37}$ 'Proof that these hormonal substances alter gut function during exercise is lacking, but many of the changes are provocative. ${ }^{4}$

Neurogenic effects are possible, though difficult to study; little work has been done on this aspect.

Simple mechanics may also be involved; the 'jiggling' of jogging can hardly be without effect. '[There is no need to] invoke sophisticated hormonal explanations. . . . An upright posture, jiggling of the colonic contents and the effect of gravity may all move stool into the rectum and

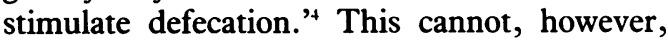
account for the clear effect of cycling, where the torso is stationary on an exercise bicycle.

The results of this study may perhaps give a clue to the basis of the relative protection against large bowel cancer conferred by life time exercise,${ }^{3-8}$ although this is no more than speculation at present.

Moderate exercise, both cycling and jogging, considerably accelerates whole gut transit, an effect which seems to be largely unrelated to alterations in dietary fibre and fluid intake. The mechanisms remain unclear, and we are really little further than Puch in 1794, who considered that exercise "helps to throw down wind from the bowels. . . . It also serves . . . as an evacuant, and a diversion by which artifices the humours are put into conditions of flying off without the danger of bringing on spasms (Puch J. Treatise of the Science of Muscular Action, quoted by Sullivan ${ }^{+}$).

Dr K W Heaton, University of Bristol, provided much advice in the early stages of this project. Dr P Sarelli, Department of Cardiology, Baragwanath Hospital, and Professor G Rogers, Department of Physiology, University of the Witwatersrand, kindly permitted use of the ergometers and treadmills in their departments.

1 Dahl R. Revolting rhymes. London: Jonathan Cape, 1982.

2 Fogoros RN. 'Runner's trots': Gastrointestinal disturbances in runners. FAMA 1980; 243: 1743-4.

3 Sullivan SN. The gastrointestinal symptoms of running. $N$ Englf Med 1981; 304: 915.

4 Sullivan SN. The effect of running on the gastrointestinal tract. F Clin Gastroenterol 1984; 6: 461-4.

5 Scheuer J, Tipton CM. Cardiovascular adaptations to physical training. Annual Review of Physiology 1977; 39: 221-51.

6 Shephard RJ. Exercise physiology. Toronto: Decker, 1987.

7 Hinds JP, Stoney B, Wald A. Does gender or the menstrual cycle affect colonic transit? A m F Gastroenterol 1989; 84: 123 6.

8 Rees WDW, Rhodes J. Altered bowel habit and menstruation. Lancet 1976; ii: 475 .

9 Turnbull GK, Thompson DG, Day S, Martin J, Walker E, Lennard-Jones JE. Relationship between symptoms, menstrual cycle and orocaecal transit in normal and constipated women. Gut 1989; 30: $30-4$.

10 Wyman JB, Heaton KW, Manning AP, Wicks ACB. Variability of colonic function in healthy subjects. Gut 1978; 19: 146-50.

11 Davies GJ, Crowder M, Reid B, Dickerson JWT. Bowel function measurements of individuals with different eating habits. Gut 1986; 27: 16t-9.

12 Cummings JH, Jenkins DJA, Wiggins HS. Measurement of 
the mean transit time of dietary residue through the human gut. Gut 1976; 17: 210-8.

13 Bloom SR, Johnson RH, Park DM, Rennie MJ, Sulaiman WR. Differences in the metabolic and hormonal responses to exercise between racing cyclists and untrained individuals. $\mathcal{F}$ Physiol 1976; 258: 1-18.

14 Bingham SA, Cummings JH. Effect of exercise and physical fitness on large intestinal function. Gastroenterology 1989; 97 $1389-99$.

15 Campbell JMH, Mitchell GD, Powell ATW. The influence of exercise on digestion. Guy's Hosp Rep 1928; 78: 279-93.

16 Hellebrandt FA, Tepper RH. Studies on the influence of exercise on the digestive work of the stomach. II. Its effect on emptying time. Am $\mathcal{f}$ Physiol 1934; 107: 355-63.

17 Fordtran JS, Salting B. Gastric emptying and intestina absorption during prolonged severe exercise. $7 \mathrm{Appl}$ Physiol 1967; 23: 331-5.

18 Costill DL, Salting B. Factors limiting gastric emptying during rest and exercise. F Appl Physiol 1974; 37: 679-83.

19 Feldman M, Nixon JV. Effect of exercise on postprandia gastric secretion and emptying in humans. $\mathcal{f}$ Appl Physiol gastric secretion
$1982 ; 53: 851-4$.

20 Carrio I, Estorch M, Serra-Grima R, et al. Gastric emptying in marathon runners. Gut 1989; 30: 152-5.

21 Cammack J, Read NW, Cann PA, Greenwood B, Holgate AM Effect of prolonged exercise on the passage of a solid meal though the stomach and small intestine. Gut 1982; 23: 95761 .

22 Evans DF, Foster GE, Hardcastle JD. Does exercise affect small bowel motility in man? Gut 1983; 24: A1012.

23 Meshkinpour H, Kemp C, Fairshter R. Effect of aerobic exercise on mouth-to-caecum transit time. Gastroenterology 1989; 96: 938-41.

24 Porter AMW. Do some marathon runners bleed into the gut? $B M \mathcal{F} 1983 ; 287: 1427$.

25 Stewart JG, Ahlquist DA, McGill DB, et al. Gastrointestinal blood loss and anaemia in runners. Ann Intern Med 1984 100: 843-5.

26 McMahon LF, Ryan MJ, Larson D, Fisher RL. Occult gastrointestinal blood loss in marathon runners. Ann Intern Med 1984; 100: 846-7.

27 Wade OL, Combes B, Childs AW, Wheeler HO, Cournand A Bradley SE. The effect of exercise on the splanchinic blood flow and splanchnic blood volume in normal man. Clin S 1956; 15: 457-63.

28 Rowell LB, Blackman JR, Bruce RA. Indocyanine green clearance and estimated hepatic blood flow during mild exercise to maximal exercise in upright man. $\mathcal{F}$ Clin Invest 1964; 43: $1677-90$.
29 Clausen JP. Effect of physical training on cardiovascular adjustments to exercise in man. Physiol Rev 1977; 57: 779815 .

30 Hilsted J, Galbo H, Sonne B, et al. Gastroenteropancreatic hormonal changes during exercise. Am 7 Physiol 1980; 239 G136-40.

31 Brandsborg O, Christensen NJ, Galbo H, Brandborg $M$ Lovgren NA. The effect of exercise, smoking and propanolol on serum gastrin in patients with duodenal ulcer and in vagotomized subjects. Scand $\mathcal{F}$ Clin Lab Invest 1978; 38 $441-6$.

32 Galbo H, Holst JJ, Christensen NJ. Glucagon and plasma catecholamine responses to graded and prolonged exercise in man. 7 Appl Physiol 1975; 38: 70-6.

33 Hartley LH, Mason JW, Hogan RP, et al. Multiple hormona responses to prolonged exercise in relation to physical training. F Appl Physiol 1972; 33: 607-10.

34 Banister EW, Griffiths J. Blood levels of adrenergic amines during exercise. F Appl Physiol 1972; 33: 674-6.

35 Sullivan SN, Champion MC, Christofides ND, et al. The gastrointestinal regulatory peptide changes of long distance gastrointestinal regulatory peptide changes
running. Phys Sports Med 1984; 12: 77-82.

36 Demers LM, Harrison TS, Halbert DR, Santen RJ. Effect of prolonged exercise on plasma prostaglandin levels. Prostagland Med 1981; 6: 413-8.

37 Carr DB, Bullen BA, Skrinar GS, et al. Physical conditioning facilitates the exercise-induced secretion of beta-endorphin and beta-lipoprotein in women. New Engl f Med 1981; 305 : $560-3$.

38 Huseman B, Neubauer MG, Duhme C. Sitzender Taetigkeit und Rektum-sigma-karzinom. Onkologie 1980; 4: 168-71.

39 Garabrant DH, Peters JM, Mack TM, Bernstein L. Job activity and colon cancer risk. Am F Epidemiol 1984; 119 1005-14.

40 Vena JE, Graham S, Zielezny M, Swanson MK, Barnes RE Nolan J. Lifetime occupational exercise and colon cancer. Am f Epidemiol 1985; 122: 357-65.

41 Gerhardsson $M$, Norell SE, Kirivanta H, Pedersen NL Ahlbom A. Sedentary jobs and colon cancer. Am $\mathcal{F}$ Epidemio Ahlbom A. Sedentar

42 Wy AH, Paganini-Hill A, Ross PK, Henderson BE. Alcohol physical activity and other risk factors for colorectal cancer: A prospective study. Br $\mathcal{F}$ Cancer 1987; 55: 687-94.

43 Frisch RE, Wyshak G, Albright NL, et al. Lower lifetime occurrence of breast cancer and cancers of the reproductive system among former college athletes. Am $\mathcal{F}$ Clin Nutr 1987 45: $328-35$. 